\title{
Automated Time-lapse ERT for Improved Process Analysis and Monitoring of Frozen Ground
}

\author{
C. Hilbich, ${ }^{1,2 *}$ C. Fuss ${ }^{3}$ and C. Hauck ${ }^{4}$ \\ ${ }^{1}$ Geographical Institute, University of Jena, Germany \\ 2 Geographical Institute, University of Zurich, Switzerland \\ ${ }^{3}$ Geolog, Augsburg, Germany \\ ${ }^{4}$ Department of Geosciences, University of Fribourg, Switzerland
}

\begin{abstract}
A new automated electrical resistivity tomography (A-ERT) system is described that allows continuous measurements of the electrical resistivity distribution in high-mountain or polar terrain. The advantages of continuous resistivity monitoring, as opposed to single measurements at irregular time intervals, are illustrated using the permafrost monitoring station at the Schilthorn, Swiss Alps. Data processing was adjusted to permit automated time-effective handling and quality assessment of the large number of 2D electrical resistivity profiles generated. Results from a one-year dataset show small temporal changes during periods with snow cover, and the largest changes during snowmelt in early summer and during freezing in autumn, which are in phase with changes in either near-surface soil moisture or subsurface temperature. During the snowmelt period, spatially variable infiltration processes were observed, leading to a rapid increase in soil moisture and corresponding decrease in electrical resistivity over a period of a few days. This infiltration led to the onset of active-layer thawing long before the seasonal snow cover vanished. Statistical analyses showed that both spatial and temporal variability over the course of one year are similar, indicating the significance of spatial heterogeneity regarding active-layer dynamics. As a result of its cost-effective ability to monitor freezing and thawing processes even at greater depths, the new A-ERT system can be widely applied in permafrost regions, especially in the context of long-term degradation processes.
\end{abstract}

KEY WORDS: electrical resistivity tomography (ERT); continuous monitoring; permafrost; Schilthorn; infiltration processes

\section{INTRODUCTION}

Determining the subsurface ice and unfrozen water content in cold regions is an important task in many cryospheric studies, but especially for permafrost or seasonally frozen ground where limited insight can be gained from surface observations. Geophysical methods are often the only possibility for visualising and quantifying the 2D subsurface characteristics in relation to the spatio-temporal evolution of subsurface ice content, especially that caused by climate variability or change (Hilbich et al., 2008a). The successful application of geophysical methods in recent years has led to increasingly sophisticated approaches including 2D and $3 \mathrm{D}$ monitoring to quantify changes in the ice and unfrozen water content of the subsurface (Marescot et al., 2003; * Correspondence to: C. Hilbich, Geographical Institute, University of
Zurich, Switzerland. E-mail: chilbich@ geo.uzh.ch
French and Binley, 2004; Fortier et al., 2008; Kneisel et al., 2008; Hausmann et al., 2007; Hilbich, 2010; Hauck et al., 2011).

The application of electrical techniques has been especially successful due to the great sensitivity of electrical resistivity to the phase change between unfrozen water and ice. Electrical resistivity tomography (ERT) is often favoured due to its comparatively easy and rapid data processing, its robustness against ambient noise, and its good performance even in harsh, cold and heterogeneous environments (cf. Hauck and Kneisel, 2008). Consequently, ERT monitoring has now become a standard tool in permafrost studies.

Despite its success, ERT monitoring has not been conducted continuously, mainly due to logistical constraints. These include the need for access to the site (often impossible in winter), the availability of instruments and manpower, challenging weather conditions and so on. ERT 
monitoring is now included within the Swiss permafrost monitoring network PERMOS (Hilbich et al., 2008b; PERMOS, 2009), but obligatory measurements are usually restricted to end-of-summer measurements to analyse long-term changes in ice content. These measurements are usually conducted between the end of August and midSeptember, when the unfrozen layer is close to its deepest and the snow cover has not yet arrived, permitting access to field sites. However, due to logistical constraints, measurements cannot be conducted on the same date at all monitoring stations or on the same date every year. Consequently, uncertainties may exist regarding data interpretation because measurements on single days (instead of monthly mean values) have to be used for the long-term climate impact analyses.

It is also challenging to compare temporally sparse ERT datasets with continuous long-term climate data, such as air/ground temperature or snow cover thickness. Climate studies generally require the analysis of statistically meaningful properties, such as maximum/minimum values and monthly or annual mean values, which cannot be determined using temporally sparse measurements made at irregular intervals. Moreover, the accuracy of time-lapse ERT inversions can be seriously affected by the presence of strong resistivity contrasts (Hilbich et al., 2009), generated by the long time intervals between consecutive measurements. Finally, continuous subsurface data are needed for input and validation of subsurface permafrost models as well as for the analysis of many thawing-related permafrost processes that take place on shorter timescales (e.g. meltwater infiltration, development of zero-curtain) (Westermann et al., 2009; Scherler et al., 2010; Zhang et al., 2010).

The need for continuous ERT monitoring data in combination with the logistical problems of conducting measurements in high alpine terrain on a regular basis led to the development of an automated ERT (A-ERT) monitoring system, which was installed in April 2009 at the Schilthorn monitoring site in the Swiss Alps. The aim was to develop a completely autonomous ERT system for high-mountain and polar research, which is easily adaptable for different temporal and spatial scales.

In this paper, we present the specifications of the new monitoring system, the automated data-processing steps to filter, de-spike and invert a large number of ERT datasets, and the first year of results from Schilthorn and their links to temperature and water content measurements.

\section{FIELD SITE AND EXPERIMENTAL SETUP}

The first A-ERT prototype was installed at Schilthorn, located in the Bernese Alps, Switzerland, with the summit at $2970 \mathrm{~m}$ asl (Figure 1). The lithology of Schilthorn is dominated by deeply weathered limestone schists forming a surface layer of mainly sandy and gravelly debris up to $5 \mathrm{~m}$ thick across the whole summit area. The measurements at Schilthorn are part of PERMOS, including three boreholes
(14 m vertical, $100 \mathrm{~m}$ vertical and $100 \mathrm{~m}$ inclined) with continuous ground temperature measurements, which were drilled within the Permafrost and Climate in Europe (EU PACE) project in 1998 and 2000 (PERMOS, 2009).

A permanent ERT monitoring profile was installed in 1999 in the immediate vicinity of the boreholes (Hauck, 2002; Hilbich et al., 2008a). This monitoring system has been included in the PERMOS programme since 2005 with up to 10 measurements per year. For long-term interannual comparisons (the aim of PERMOS), at least one measurement is necessary in each August/September. The 58-m long E-W ERT monitoring profile is located on the northern slope of the Schilthorn crest (Figure 1), and consists of a fixed array of 30 electrodes spaced $2 \mathrm{~m}$ apart that are connected by buried cables to a manual switchbox where the resistivity meter (currently either a SYSCAL, Iris Instruments, or a Geotom, Geolog) can be connected. Measurements can be conducted with varying electrode configurations, including Wenner, Wenner-Schlumberger and dipole-dipole. A second line, established in 2005, $188 \mathrm{~m}$ long and oriented $\mathrm{N}-\mathrm{S}$, crosses the first at right angles and leads from $20 \mathrm{~m}$ below the borehole across the Schilthorn crest onto the southern slope. This paper, however, focuses almost exclusively on the E-W horizontal profile.

The borehole data show that the permafrost is at least $100 \mathrm{~m}$ thick, but ground temperatures are close to $0{ }^{\circ} \mathrm{C}$ (PERMOS, 2009). Maximum active-layer depths recorded since the start of measurements in 1999 are generally around $5 \mathrm{~m}$, but during the exceptionally warm summer of the year 2003 the active-layer depth increased to $8.6 \mathrm{~m}$, reflecting the potential for degradation of this warm permafrost (Hilbich et al., 2008a).

The Schilthorn was chosen as the test site within the project cluster Sensitivity of Mountain Permafrost to Climate Change (funded by the German Research Foundation) to undertake temporal high-resolution measurements to detect and quantify freezing and thawing processes. Besides the newly developed A-ERT system, these measurements include soil moisture and additional soil temperature measurements at various depths at two different locations along the ERT profile. For these, newly developed soil moisture sensors called SISOMOP (simplified soil moisture probe) were installed, which measure and log soil moisture and soil temperature at predefined time intervals. The values of absolute soil moisture derived from the SISOMOP sensors have variable errors depending on soil type, but the accuracy of relative soil moisture changes is better than 2 per cent (Schlaeger et al., 2005; Krauss et al., 2010).

\section{A-ERT SYSTEM}

Continuous ERT measurements over pre-defined but limited time periods have been reported previously in the literature (Aaltonen and Olofsson, 2002; French and Binley, 2004; LaBrecque et al., 2004; Versteeg et al., 2004; Sjödahl et al., 2008; Kuras et al., 2009; Ogilvy et al., 2009), but 


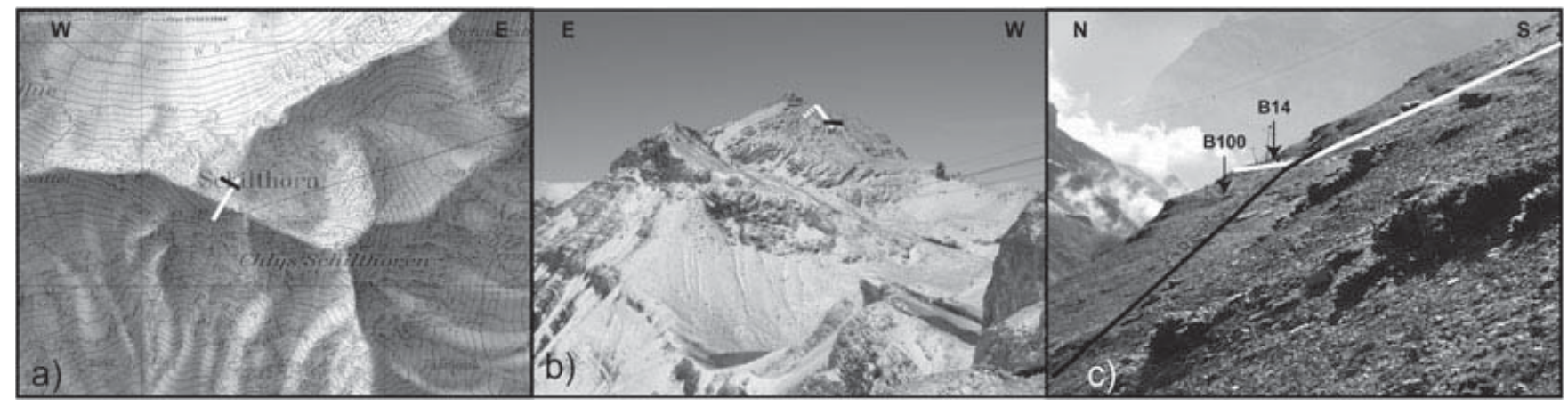

Figure 1 (a) Map (PK25, (C) Swisstopo 2007) and (b and c) photographs of the Schilthorn field site with location of the automated electrical resistivity tomography (A-ERT) profile (black), boreholes (B14 and B100) and the additional ERT line across the Schilthorn ridge (white).

no ERT system for automated and continuous long-term measurements in alpine or polar terrain has been available. The new A-ERT system was developed in close collaboration with the company Geolog (Germany) for cost-effective applications in polar and high-mountain terrain (robust and water-proof design, lightning protected, remotely controlled). It is based on an existing multi-electrode resistivity instrument (Geotom) with up to 100 electrodes, a solar panel-driven battery and wireless data transfer to a base station. As a result of the resistive environment, power consumption is low, and a $10-\mathrm{W}$ solar panel and a $24-\mathrm{Ah} 12-\mathrm{V}$ battery are sufficient to power the system at the Schilthorn site, even during winter. An external computer controls the measurements of the various quadrupoles. This computer was located at the base station Birg (2677 m asl; see Figure 2), with direct line of sight (2-km distance between transmitting and receiving antennae) to the measurement site to enable wireless data transfer.

In its current setup (since April 2009), one Wenner, one Wenner-Schlumberger and one dipole-dipole measurement are conducted per day in summer. To save battery power in winter, only daily Wenner and Wenner-Schlumberger measurements are conducted, complemented by weekly dipole-dipole measurements.

The interval of the measurements, electrode configuration, number of stacks and optional induced polarisation (IP) measurements can be defined via controlling software at the base station computer. The measurement procedure takes less than 3 minutes for a typical Wenner array of the 30-electrode profile originally installed by Hauck (2002).

\section{Specifications of the Geotom-Res-IP Measuring System}

The transmitter input signal source is a commutated constant current between $1 \mu \mathrm{A}$ and $200 \mathrm{~mA}$ controlled by a maximum output voltage of $350 \mathrm{~V}$ with selectable frequencies of $0.52,1.042,2.083,4.167,8.333,12.5$ and $25.0 \mathrm{~Hz}$.

The measuring principle of the system receiver is based on a lock-in amplification of the in-phase (resistivity) and out-of-phase $90^{\circ}$ phase-shifted (IP) signals. The main operational element is the multiplication of the input signal with a reference signal and a low-pass filtering, followed by digital averaging over at least one full cycle.

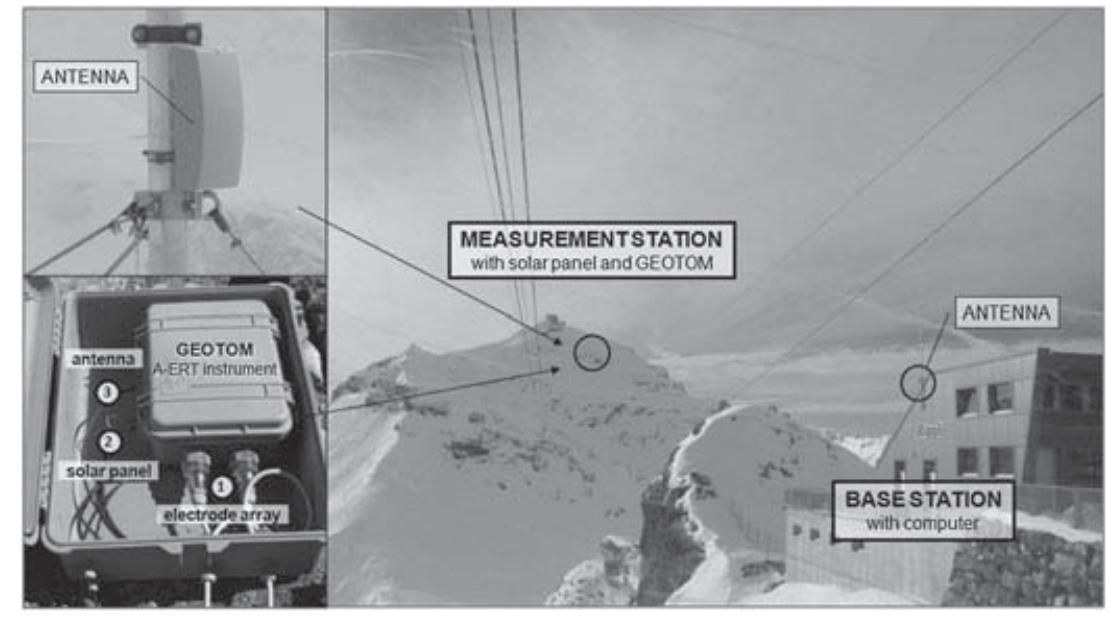

Figure 2 Overview of the automated electrical resistivity tomography (A-ERT) monitoring system and its installation at Schilthorn. The cable car station in the foreground of the photograph is the base station Birg. 
The output signal of this amplification is a DC voltage, which is ideally proportional to the source input signal voltage and the cosine of the phase shift between the input and the reference signal.

Selectable discrete frequencies allow optimal suppression of noise sources caused by commercial frequencies at $50 \mathrm{~Hz}$ or $162 / 3 \mathrm{~Hz}$, and their high-order harmonics. The transmitter and reference frequencies of the lock-in amplifier would have to be adapted for use in countries with other commercial frequencies.

\section{PERFORMANCE, DATA QUALITY AND PROCESSING}

The new system performed well over the course of the first year. The only major problem was frequent power interruption due to lightning and maintenance work at the base station Birg, which led to data gaps because the controlling A-ERT computer had to be manually restarted. A buffered battery power supply circuit and direct internet connection to check the status of the system will be installed in the near future to overcome this problem. The harsh weather conditions had no impact on antennae communication and system performance.

Apart from equipment reliability, it is important to note that a fundamental precondition for successful application of an A-ERT system is adequate electrode contact throughout the year. Electrode contact in ERT surveys in permafrost terrain often must be improved manually by surface wetting or adding electrodes to reduce contact resistance (cf. Kneisel and Hauck, 2008). Ensuring good electrode contact throughout the year may be the most critical factor for the applicability of an A-ERT system to a specific site.

\section{Data Quality}

Electrode contact along the profile line was both good and temporally stable, with contact resistances of less than 10 $\mathrm{k} \Omega \mathrm{m}$ even during six to seven months with snow cover and sub-zero temperature conditions. Consequently, little maintenance of the electrode line was required, yielding comparable conditions during the whole year.

In a few cases, changing surface conditions at the electrodes led to unstable values, which had to be identified and deleted from the ERT dataset to ensure good inversion results. As expected, data from the A-ERT monitoring are of lower quality than manual measurements, because no manual electrode check and corresponding improvement of contact resistance is possible prior to the measurements. This characteristic of A-ERT monitoring datasets makes an automated filtering algorithm necessary (see below).

\section{Data Processing}

The A-ERT system currently generates at least one complete ERT dataset per day (135 apparent resistivity raw data points in Wenner configuration). This volume of data meant that new automated data-processing algorithms had to be developed to handle quality control, data inversion and interpretation. This automated data processing includes:

- Filtering and de-spiking of the measured apparent resistivity datasets.

- Calculation of mean apparent resistivity values for different depth levels.

- Batch-inversion of the filtered apparent resistivity datasets.

- Post-processing of the inverted ERT datasets.

The filtering and de-spiking are conducted in three steps. Initially, all data points with physically implausible values (e.g. negative potential differences $(\mathrm{U}<0 \mathrm{mV})$ or too low current flow with simultaneously high potentials $(\mathrm{I} \leq 0.1 \mathrm{~mA}$ and $\mathrm{U}>100 \mathrm{mV}$ ) are eliminated. Secondly, site-specific criteria are used to identify further measurement errors or electrode contact problems: For Schilthorn, we excluded all data points with standard deviations $>2$ per cent after stacking and with $\rho_{\mathrm{a}}>4000 \Omega \mathrm{m}$ and $\rho_{\mathrm{a}}<$ $450 \Omega \mathrm{m}$. These criteria are based on the experience of more than 150 manual ERT measurements within the last 10 years (Hilbich et al., 2008a). Thirdly, a temporal de-spiking filter is applied to the time series to remove unrealistic outliers without disturbing the natural variations. This de-spiking filter is based on a threshold of 20 per cent (see Sjödahl et al., 2008) and was adapted using corresponding soil moisture values to avoid removing real features instead of measurement errors. According to this algorithm, a data point at time step $n+1\left(\rho_{n+1}\right)$ that differs from the value at time step $n\left(\rho_{n}\right)$ by \pm 20 per cent is deleted from the time series. To account for gaps in the time series, a temporal threshold of five days is included so that points are not filtered for temporal gaps greater than five days.

The first two steps of this filtering procedure remove the majority of bad data points based on the criteria usually applied in manual pre-processing of raw ERT profile data (cf. Kneisel and Hauck, 2008). The third step addresses outliers in the temporal evolution of each quadrupole and eliminates most of the remaining spikes in the time series. A comparison of raw and filtered apparent resistivity data points for the whole time series (Wenner array) and for all nine depth levels showed that almost all outliers were eliminated (Figure 3). In total, less than 2 per cent of all data were removed by the filter procedure, demonstrating the high overall quality of the complete A-ERT dataset (Table 1). Most of these spikes were generated during winter and spring measurements due to occasionally high contact resistances at single electrodes and the already high data quality improved with thawing of the surface after snowmelt.

Following filtering, spatial and temporal mean apparent resistivities are calculated and analysed regarding seasonal or interannual resistivity changes. Apparent resistivities can be more useful than inverted specific resistivities for monitoring near-surface processes (e.g. infiltration) because 

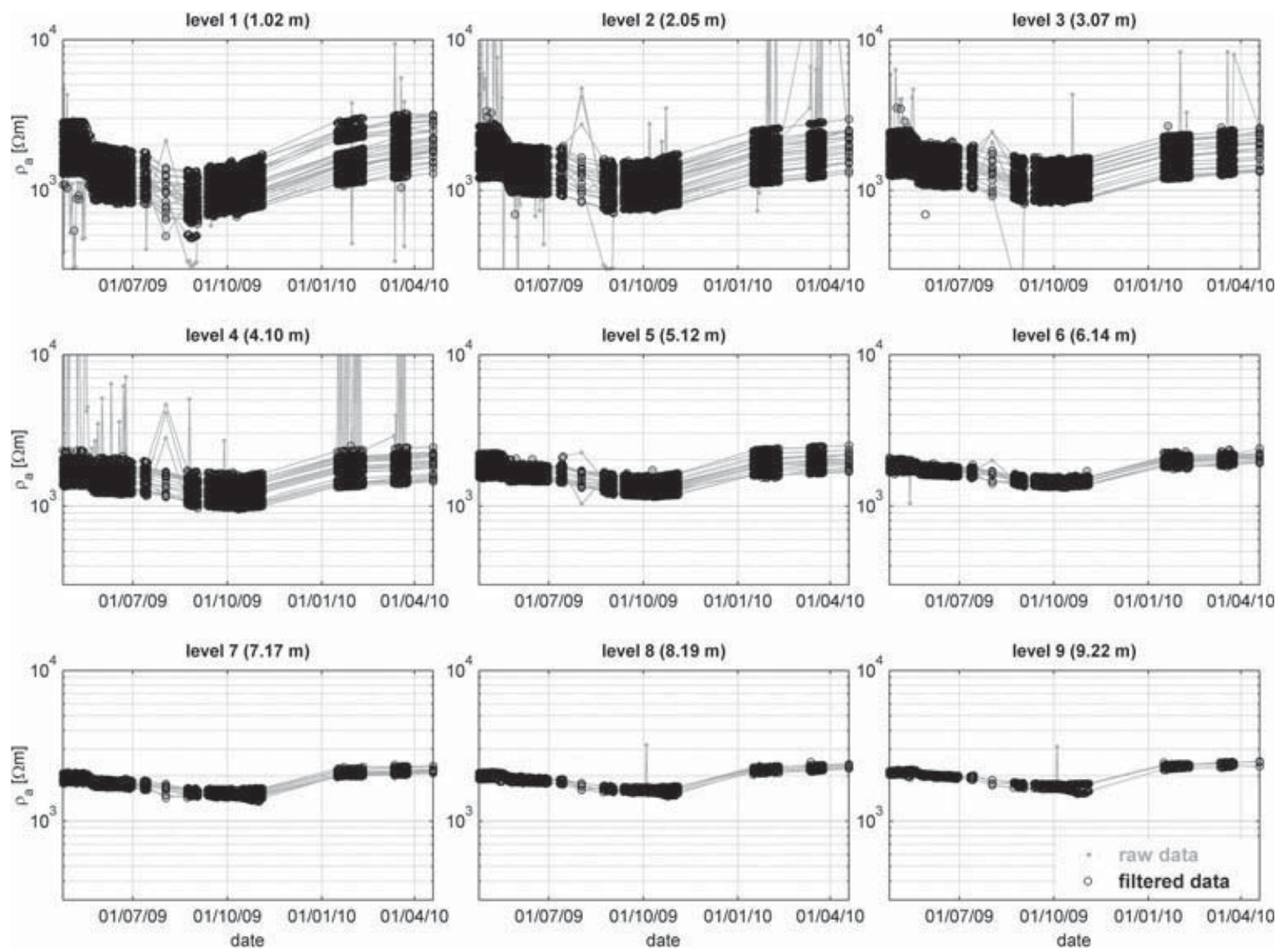

Figure 3 Raw (grey) and filtered (black) apparent resistivity data points from the automated electrical resistivity tomography profile line at Schilthorn for all nine depth levels (pseudo-depths shown in brackets) from April 2009 to April 2010. Note that most of the outliers (grey spikes) are generated during winter and spring measurements due to occasionally high contact resistances.

the latter are sometimes affected by inversion artefacts if large temporal changes occur (Hilbich et al., 2009).

In the next processing step, the apparent resistivity datasets are automatically inverted using a batch routine within the

Table 1 Characteristics of the A-ERT dataset (24 April 2009 to 19 April 2010).

\begin{tabular}{lc}
\hline Number of ERT datasets & 180 \\
\hline Total number of data points & 24300 \\
Total number of data points after & 23905 \\
filtering & $(1.62 \%$ deleted) \\
$\begin{array}{l}\text { Spatial variability (standard deviation } \\
\text { per quadrupole over time) }\end{array}$ & $200-600 \Omega \mathrm{m}$ \\
$\begin{array}{l}\text { Temporal variability (standard deviation } \\
\text { per date for all quadrupoles) }\end{array}$ & $250-400 \Omega \mathrm{m}$ \\
$\begin{array}{l}\text { Total minimum apparent resistivity } \\
\text { (after filtering) }\end{array}$ & $600 \Omega \mathrm{m}$ \\
$\begin{array}{l}\text { Total maximum apparent resistivity } \\
\text { (after filtering) }\end{array}$ & $3507 \Omega \mathrm{m}$ \\
$\begin{array}{l}\text { Total median apparent resistivity } \\
\text { (after filtering) }\end{array}$ & $1529 \Omega \mathrm{m}$ \\
\hline
\end{tabular}

software RES2DINV. To ensure comparability of the results, the same set of inversion parameters is used for all ERT datasets. For Schilthorn, this set includes:

1. the robust inversion scheme (L1-norm);

2. a model with 1.5-fold depth of the median depth of investigation of the largest array spacing used (usually estimated after Edwards, 1977); the so-called 'extended model', as well as a reduction of edge effects to reduce the inclusion of artefacts within the model region of interest (i.e. the uppermost $10 \mathrm{~m}$ );

3. a slightly increased damping factor with depth compared to the standard parameter (factor 1.15); and

4. a fixed termination of the inversion after the $3 \mathrm{rd}$ iteration, since the absolute error has then usually already decreased to 2-4 per cent.

As the software RES2DINV cannot invert more than 12 ERT datasets at the same time and a reference model is difficult to define for continuous measurements, no time-lapse inversions were performed. A comparison of time-lapse and individual inversions for annual and seasonal time series from the Schilthorn profile showed negligible differences 
for datasets with small to medium resistivity changes (not shown).

Finally, automated post-processing of the inverted ERT datasets was performed, including: (1) the generation of time series of specific resistivity values at specific locations (e.g. by plotting so-called virtual boreholes); (2) the calculation and plot of temporal resistivity differences (time-lapse tomograms); and (3) the calculation of statistical measures (i.e. median tomograms and standard deviations).

\section{RESULTS}

One of the major advantages of the automated system is the regular collection of ERT datasets for different electrode configurations. A joint inversion of, for example, Wenner, Schlumberger and dipole-dipole data considerably increases the spatial resolution and thus the reliability of the inverted tomograms. However, to demonstrate the overall performance of the A-ERT system, in this paper we examine only datasets from the Wenner measurements.

\section{Apparent Resistivity Analysis}

Table 1 gives some basic statistical properties of the oneyear Wenner dataset. The low percentage of filtered data points demonstrates the generally high quality of the complete A-ERT dataset with a low noise level. In contrast to the results from other studies in non-permafrost terrain (Aaltonen and Olofsson, 2002), spatial and temporal variability are similar, which highlights the need for both temporal and spatial analyses of the dominant processes.

Hilbich et al. (2008a) emphasised the usefulness of analysing spatial mean apparent resistivity data over different timescales (daily, monthly, seasonal and annual). Whereas daily fluctuations were found to be small, seasonal changes (i.e. freezing and thawing of the active layer with a delayed response of deeper layers to temperature forcing on the surface) could be accurately monitored. At this seasonal scale, the advancing freezing front in late winter (increasing resistivity) as well as active-layer thawing in summer (decreasing resistivity) are revealed by measurements made at roughly monthly intervals (Figure 4 ). The potential for interannual differences is shown by the minimum values in the summer 2003 due to extremely high air temperatures in the European Alps (Hilbich et al., 2008a). Analysis of interannual variability, however, depends on the choice of the measurement date, for which the long-term resistivity changes are evaluated. Minimum values over 11 years were observed in October in 2008, in September in 2002 and 2007, and as early as August in 2000 and 2003. It is not clear whether the timing of these minima is a consequence of the irregular data acquisition or the prevailing meteorological conditions. The choice of ERT datasets for timelapse resistivity inversion over several years can therefore be crucial for interpreting permafrost degradation. For the continuous A-ERT dataset of 2009 (except for the data gaps due to power failure), the minimum resistivity value can be more easily (and objectively) determined, even though the influence of precipitation events on certain dates appears pronounced and may give rise to some additional problems (e.g. the 'first' minimum in 2009 , which was caused by a heavy thunderstorm on 2 September 2009).

The benefit of the new A-ERT monitoring system is also manifested through the possibility of analysing specific processes (e.g. active-layer thaw in 2009 values). In contrast to the sporadic and irregular measurements in the preceding years, the strongly decreasing resistivities during one week in May 2009, which are due to infiltrating water from the melting snow cover, can now be clearly distinguished and quantified (see below). Resistivities continued to decrease in summer 2009 leading to a new minimum value in late autumn (Figure 4), mainly due to particularly high September and October temperatures (www.meteoswiss.ch).

\section{Inverted Specific Resistivity Analysis}

Figure 5a shows an approximately monthly selection of inverted resistivity tomograms between April 2009 and April 2010 and Figure 5b shows the resistivity changes relative to the first ERT dataset from April 2009. The resistivity pattern in the ERT monitoring profile at Schilthorn is characterised by a low resistive anomaly down to about 5-m depth in the left part of the profile, indicating finer-grained material (sand to gravel) compared to the higher resistivity values (of around $3000 \Omega \mathrm{m}$ ), indicating firm bedrock according to borehole evidence from the drilling operations. This bedrock is partly visible at the surface as weathered outcrops in the right-hand part of the profile (cf. Figure 1). Below a depth of $5 \mathrm{~m}$, values around 2000-3000 $\Omega \mathrm{m}$ indicate a homogeneous bedrock layer throughout the profile.

The largest resistivity changes during the year take place at the surface between April and May (infiltrating meltwater), at greater depths between the end of August and September (active-layer maximum), and the beginning of winter (until January) (Figure 5b). This seasonal behaviour is entirely consistent with the first seasonal measurements between 1999 and 2000 (Hauck, 2002) and can also be seen in the mean apparent resistivities per ERT dataset (Figure 4).

These general characteristics become even more evident when calculating the statistical properties of the A-ERT dataset over different time periods (Figure 6). The median of the complete A-ERT dataset again reveals the substrate characteristics mentioned above, with the low resistive anomaly in the left part of the profile and values of around $2000 \Omega \mathrm{m}$ for the host material. The corresponding standard deviation is consistently low below the near-surface layer (uppermost $2 \mathrm{~m}$ ), where the seasonal variations are less pronounced. Within the near-surface layer, variability is greatest in the right-hand part of the profile, where the bedrock emerges at the surface. These outcrops, having lower porosities than the debris in the remainder of the profile, react 


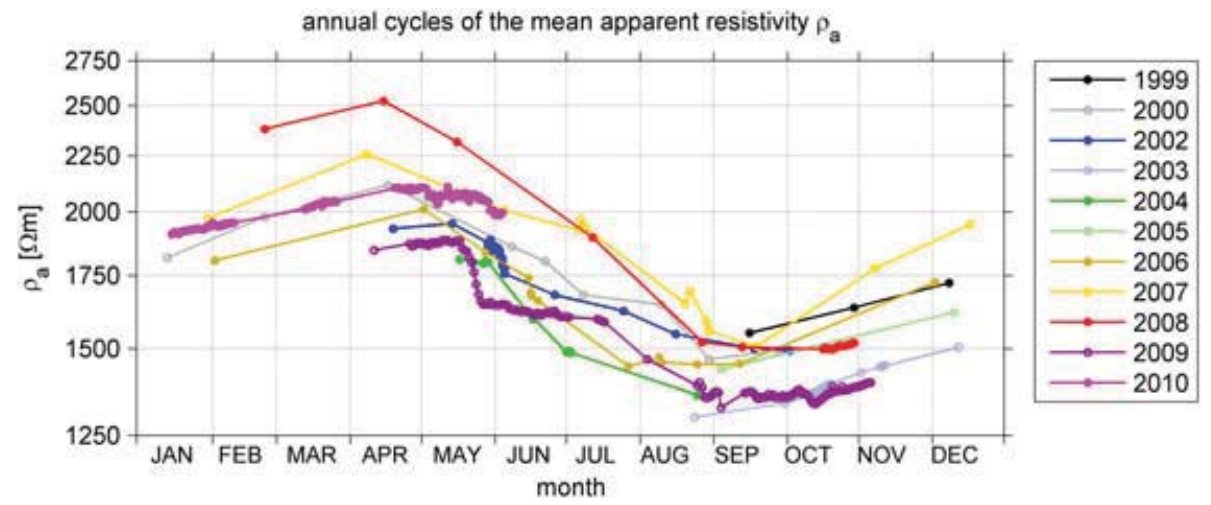

Figure 4 Annual and seasonal variation of average apparent resistivities per electrical resistivity tomography (ERT) dataset from 1999 to 2010 for the automated ERT profile at Schilthorn.

more directly to seasonal air temperature change. This effect is most pronounced in winter (defined as the period with increasing mean apparent resistivities), as the higher thermal conductivity of the bedrock leads to faster propagation of the low winter temperatures into the ground (Figure $6 \mathrm{~d}$ ). In contrast, values in summer (defined as the period with decreasing mean apparent resistivities) are less variable (Figure 6c) and primarily influenced by the period of snow cover melt in May (thawing period, Figure 6b). Although variations during this thawing period are mainly restricted to the level of thaw depth, increased variability can also be seen at greater depths in summer.

\section{DISCUSSION}

To analyse the dynamics of the active layer in more detail, we will focus on the two parts of the A-ERT profile, where the $14 \mathrm{~m}$ and $100 \mathrm{~m}$ boreholes (B14, B100) are located (cf. Figure 1). For this analysis, so-called virtual boreholes are used, which plot vertical profiles of specific resistivity, taken from the corresponding tomograms, and their temporal evolution.

\section{Annual Cycle}

Figure 7a shows the specific resistivity evolution with time in virtual boreholes at the B14 and B100 locations during April 2009 and April 2010, superimposed on the positions of the $0{ }^{\circ} \mathrm{C}$ isotherms extracted from the borehole temperatures. Figure $7 \mathrm{~b}$ shows the temperature evolution only in borehole B14.

In Figure $7 \mathrm{a}$, the unfrozen parts of the subsurface are delineated by the areas inside the $0{ }^{\circ} \mathrm{C}$ isotherms. For B100, this roughly corresponds to resistivity values around $2000 \Omega \mathrm{m}$ (transition to light blue colours), but from the yellow colours in May/June at the surface it is clear that unfrozen moisture is already present during the snowmelt season even though ground temperatures are still below zero. For B14, the different geological setting (thick debris overlying the bedrock) results in much lower resistivity values between 2-5-m depth throughout the year. At the surface and depths below the active layer, the resistivity evolution for the two virtual boreholes is similar except for small differences near the surface with slightly higher values for B100. This difference is most pronounced after the thawing season in July, as the resistivity values of the dry bedrock are higher than the corresponding values for the debris material near B14.

For both locations, the minimum resistivity values at each depth level correspond with the maximum ground temperatures and vice versa for maximum resistivities and minimum temperatures. Apart from the surface, the spread of the values is greatest immediately above the permafrost table around 5-m depth, where the absolute minimum values of $<500 \Omega \mathrm{m}$ were observed in October. This comparatively late date for the occurrence of the minima, which corresponded to the maximum active-layer thickness in the borehole, was due to an extraordinary warm autumn in Switzerland with high air temperatures in September and October (www.meteoswiss.ch).

Looking more closely at the main processes involved in seasonal active-layer thawing, Figure 8 shows apparent resistivity, unfrozen soil moisture and soil temperature at approximately the same depth at the B14 site from April to November 2009. Soil moisture is low and relatively constant during winter, with slightly higher values at $0.4-\mathrm{m}$ depth than at the surface (period I). This behaviour changes in mid-May when soil moisture (and soil temperature at 0.4-m depth) starts to increase slowly (period II), followed by an abrupt increase within only one day at the end of May. As this increase is first detected by the sensor at $0.2-\mathrm{m}$ depth, and very shortly afterwards at 0.4-m depth, we assume infiltration processes from the melting snow cover to have caused this change and the associated decrease in resistivities, and this is supported by observations of a continuous and dry snow cover on the northern slope of Schilthorn until mid-May. Soil moisture values subsequently increased continuously but slowly (period III) until mid-July, when a high-variability pattern indicates the direct influence of the atmosphere (e.g. short-wave radiation and precipitation), and therefore the complete absence of an insulating snow cover (period IV). 

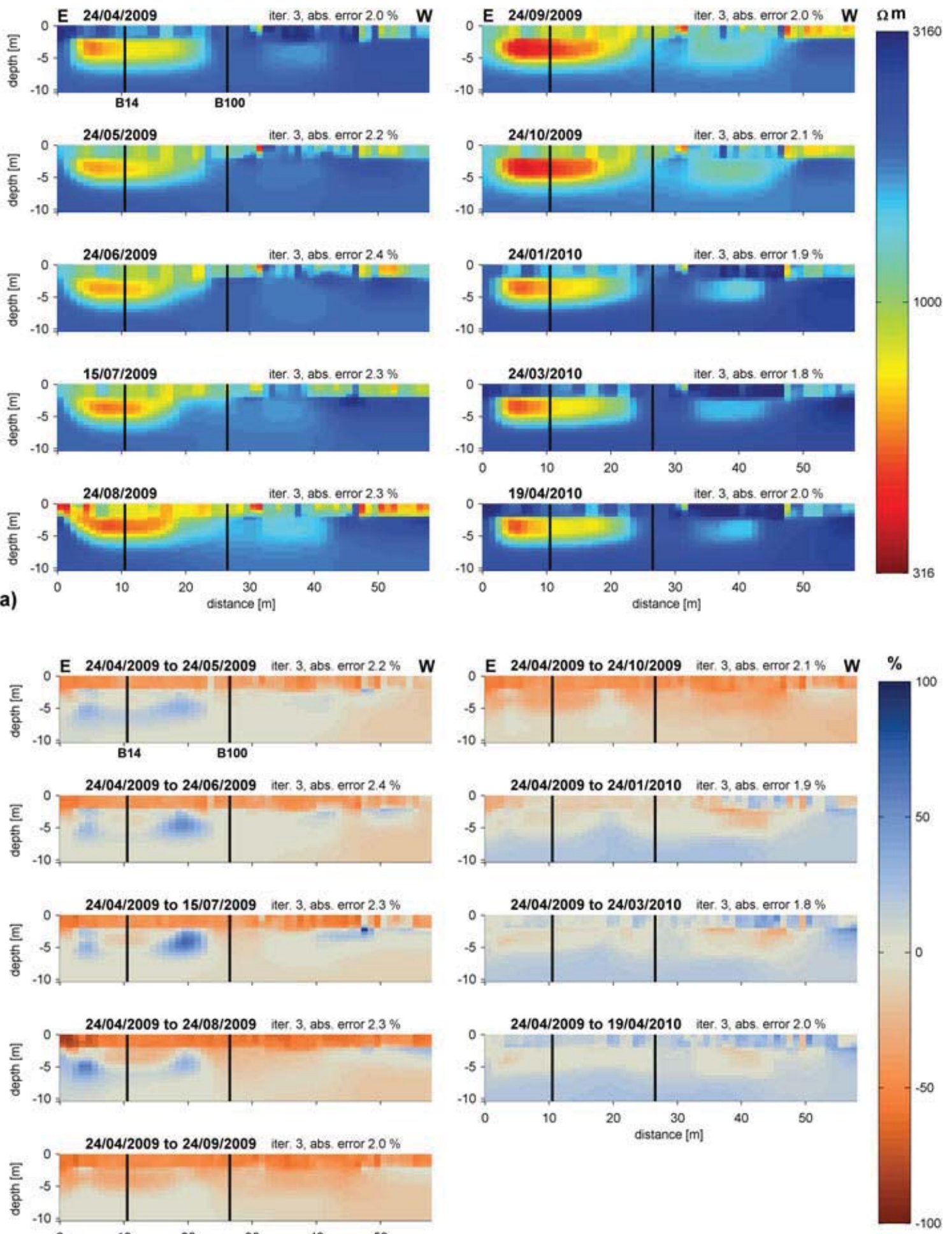

b)
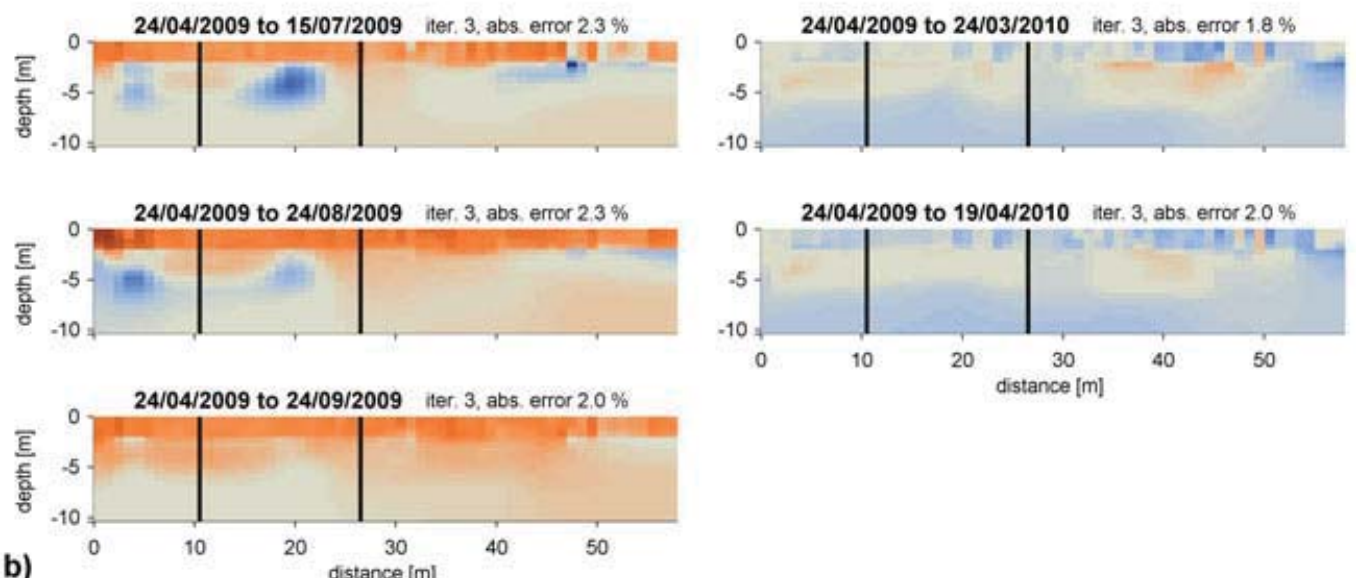

Figure 5 (a) Inverted resistivity tomograms of 10 quasi-monthly spaced electrical resistivity tomography (ERT) datasets between April 2009 and April 2010 ; and (b) relative resistivity changes based on the first ERT dataset in April 2009. Black lines indicate the position of the two boreholes: the temperatures are shown in Figure 7. Note the slightly altered intervals for July 2009 and April 2010 due to data gaps. 

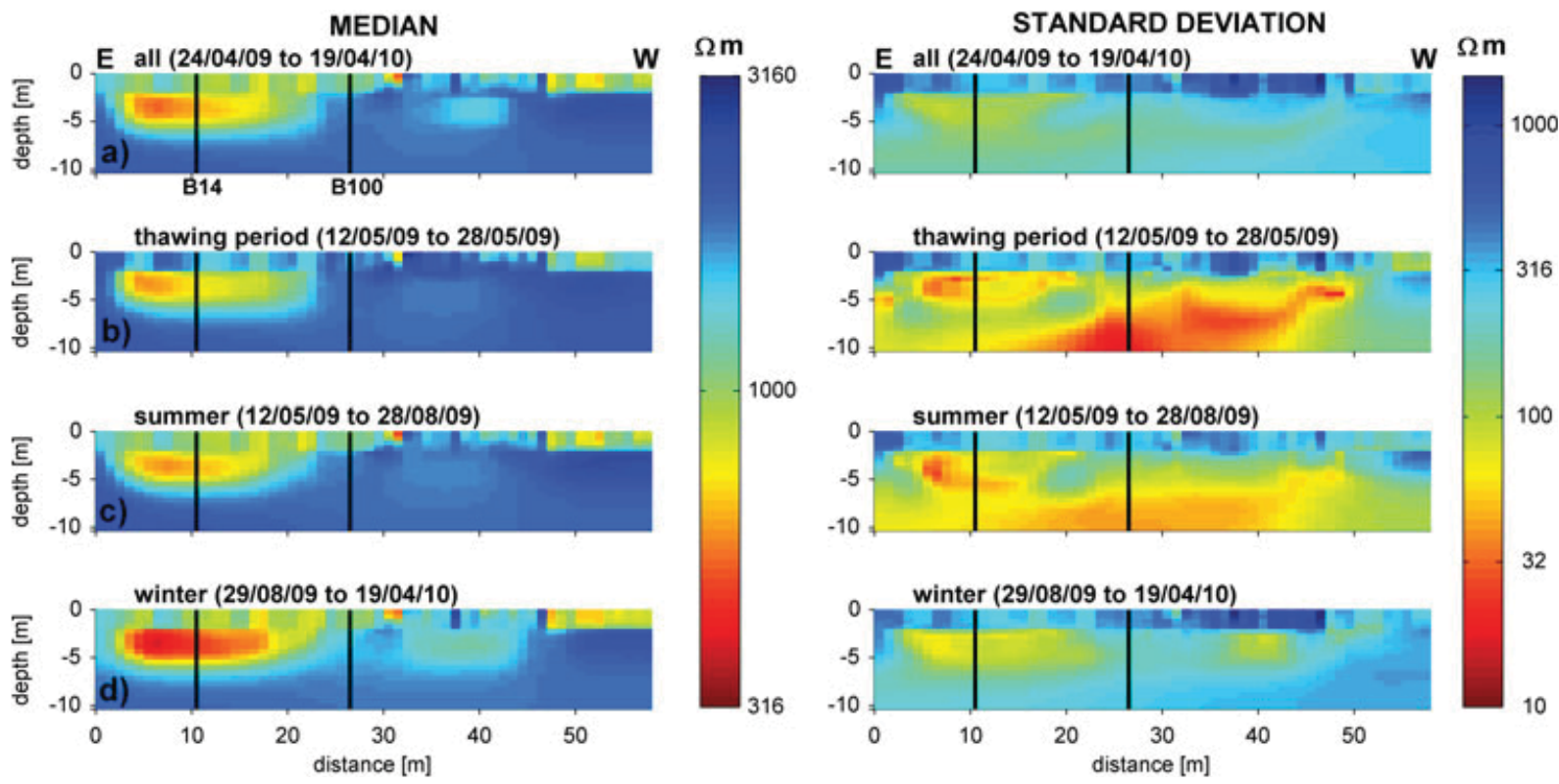

Figure 6 Median tomogram and standard deviation of each model block for: (a) the complete automated electrical resistivity tomography dataset from April 2009 to April 2010; (b) the onset of thawing of the active layer (12-28 May 2009); (c) summer (12 May 2009 to 28 August 2009 ); and (d) winter (29 August 2009 to 19 April 2010). Summer and winter are defined, respectively, as the periods with decreasing and increasing mean apparent resistivity values.

Soil temperature values (both at the soil moisture sensor and in the borehole) similarly increase in two steps towards $0{ }^{\circ} \mathrm{C}$ : slowly in mid-May, and then rapidly at the end of May, simultaneously with the sharp soil moisture increase mentioned above. Afterwards, temperatures stay within the zero-curtain for almost two months (period III), and positive temperatures are only observed at the end of June (borehole) and in mid-July (at the soil moisture sensor). The latter coincides with the onset of higher soil moisture variability attributed to the complete ablation of the snow cover and direct influence of atmospheric processes. It is notable that the small increase in soil moisture during the zero-curtain phase is in very good agreement with the anticipated increase in liquid water due to ice melt at the sensor.

The apparent resistivity time series ( $\mathrm{SCH}$, level 1$)$ at the B14 borehole site shows an inverse behaviour compared to soil moisture (Figure 8 lower): a slight decrease in apparent resistivity in mid-May (period II), a sharp decrease over only two days at the end of May (II-III) and a slight but continuous decrease in apparent resistivity until mid-July (III), when a data gap unfortunately prevents examination of the start of the snow-free period. This agreement between the two different types of observations (the in-situ soil moisture sensor and the indirect ERT method) is confirmed through the consistent evolution of apparent resistivity at the second level (grey squares) and additional data points extracted from the coincident quadrupole of the second ERT line across the Schilthorn crest (SCV, level 1, filled grey squares). This line is not automated yet, but individual ERT datasets obtained in May, July, August and September show good agreement with the horizontal ERT line.
Soil temperature varies throughout the summer with three distinct peaks at the beginning of August, in mid-August and at the end of September, whereas soil moisture shows the typical rainfall and evaporation/infiltration-induced saw-tooth pattern: a sharp increase due to rain and an asymptotic decrease due to evaporation and infiltration. Comparing soil temperature and soil moisture with resistivity shows that resistivity is not clearly related to temperature (i.e. infiltration processes are the dominant influence on resistivity change in the uppermost level during the snowfree period). It should be noted, however, that the temperature maxima coincide with the gaps in the resistivity data, restricting comparisons to a few events.

Soil temperatures start to decrease towards the freezing point in mid-October, a change that is also present in the soil moisture data, indicating the development of a continuous snow cover. Simultaneously, apparent resistivity data start to increase.

\section{Snowmelt Season 2009}

Scherler et al. (2010) recently simulated the active-layer thaw period on Schilthorn for May using a coupled heat and mass transfer model COUP and validated the results with borehole temperature data. They found that infiltrating meltwater may percolate and reach greater depths within the active layer by the accumulation of a water pool at the ground surface from the melting snow cover. When this water pool is emptied, water refreezes at the surface and the top layer is again sealed by ice, which ends the infiltration cycle. The result of this process is the transfer of heat 

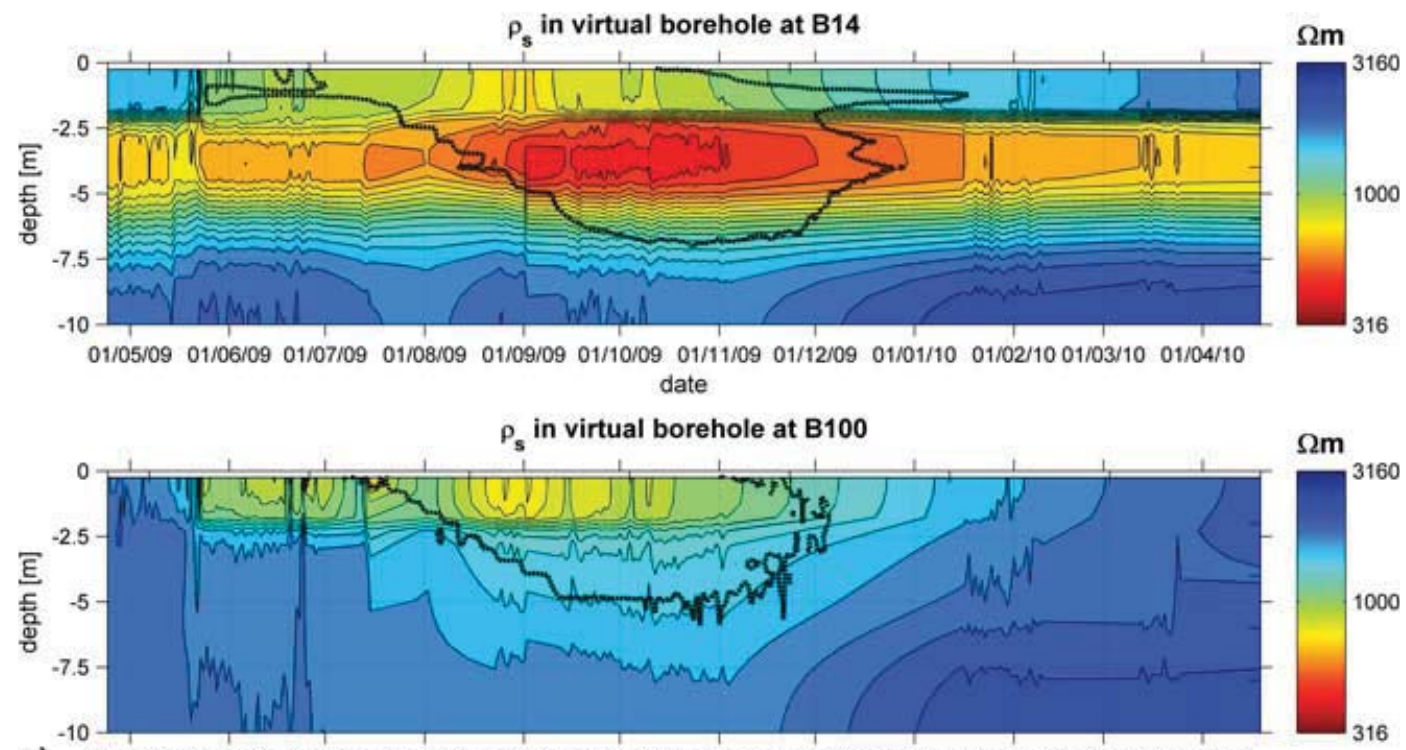

a) 01/05/09 01/06/09 01/07/09 01/08/09 01/09/09 01/10/09 01/11/09 01/12/09 01/01/10 01/02/10 01/03/10 01/04/10 date

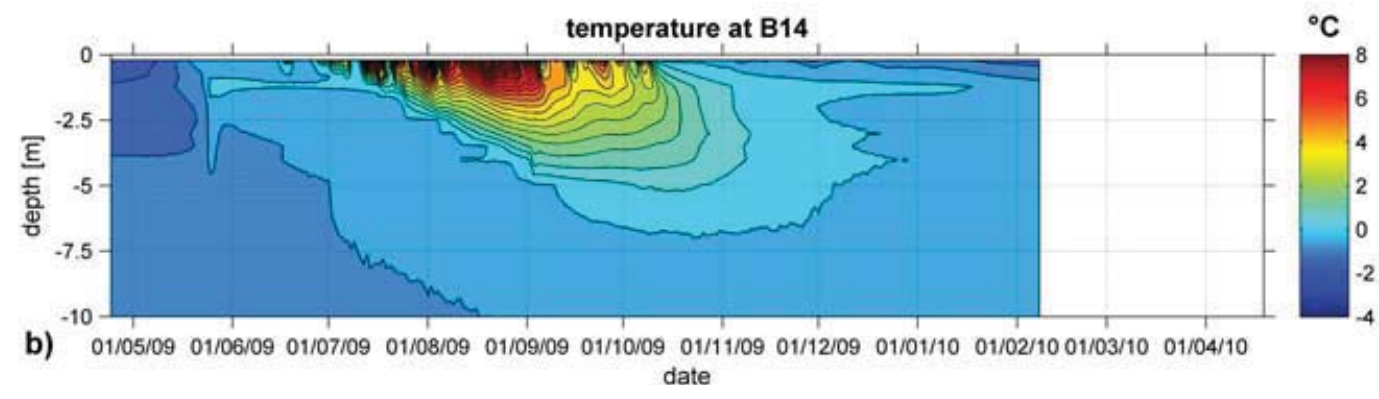

Figure 7 (a) Temporal evolution of specific resistivity in virtual boreholes at the actual boreholes B14 and B100 taken from various inverted tomograms for the period April 2009 to April 2010. The bold black lines mark the position of the $0^{\circ} \mathrm{C}$ isotherm extracted from the borehole temperatures. (b) Temperature evolution in borehole B14 between 24 April 2009 and 7 February 2010.

into the ground, an increase in the water content and a refreezing of the meltwater at the surface. The importance of surface water pools for snowmelt-induced infiltration processes into seasonally frozen soil was also described by French and Binley (2004) using a short-term ERT monitoring setup.

The availability of daily ERT results permits spatial analysis of these processes (Figure 9). Infiltration appears to start around 12 May in the right-hand side of the profile, increasing to a larger patch within the next four days. Around that time, resistivity decreases at greater depths on the left-hand side of the profile, but initially without corresponding changes at the surface. This indicates laterally dominated infiltration processes from further upslope (i.e. at right angles to the profile direction). By 22 May, the resistivity of the whole surface layer has decreased by about 20-50 per cent, but this decrease shows strong spatial heterogeneity, indicating laterally different amounts of water entering the subsurface (and/or additional thawing processes). At the same time, a resistivity increase is visible at around 5-7-m depth in the left-hand side of the profile.
As suggested by Scherler et al. (2010), this may be due to refreezing water from the infiltration process, as temperatures at 5-m depth were still around $-1.0^{\circ} \mathrm{C}$ at that time. Alternatively, this resistivity increase could be caused by the negative and still decreasing borehole temperatures at 7-m depth (not shown), which lead to a reduced unfrozen water content and thus to increasing resistivities (see, for example, Scott et al., 1990). The resistivity decrease at greater depth at the very right end of the profile is probably an inversion artefact due to the limited sensitivity of the Wenner array near the lower edges of the tomogram.

The timing of the onset of thawing at the borehole sites is best illustrated by the virtual boreholes for the period 8 to 30 May (Figure 10). The first significant reduction in resistivity at the surface occurs on 20 May for B14 leading to strongly decreasing resistivity values down to $2-2.5-\mathrm{m}$ depth, and on 22 May for B100 where decreasing resistivities are present down to 7-m depth. After a renewed small increase on 22 May, surface resistivity strongly decreased on 24 May to values around $1000 \Omega \mathrm{m}$, where it stayed until the end of this first thawing period on 30 May. Similarly, but 

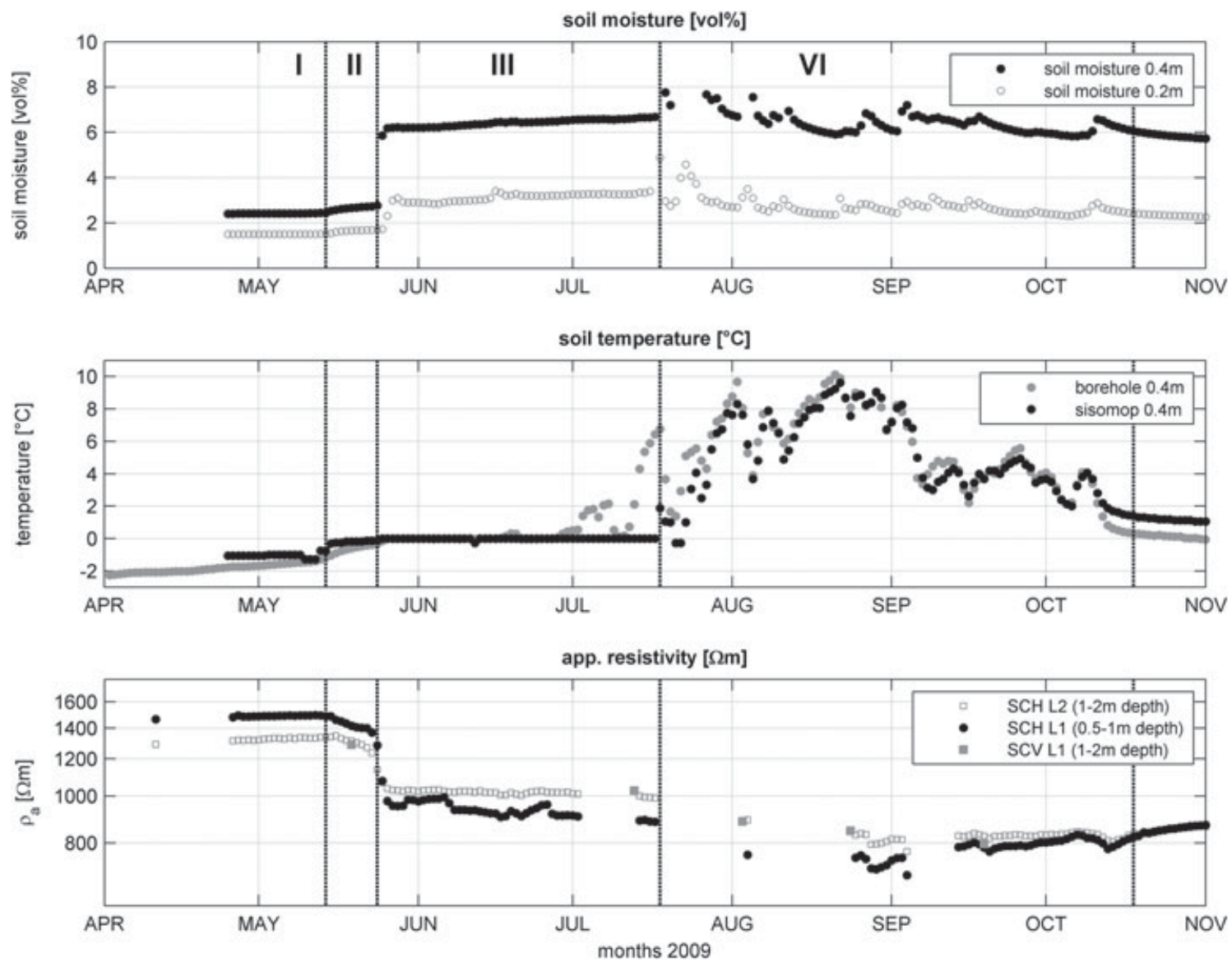

Figure 8 (Upper) Soil moisture, (middle) soil temperature (measured at coincident sites with soil moisture probe sensors (SISOMOP) as well as in the B14 borehole) and (lower) apparent resistivity for the two uppermost depth levels of the horizontal profile (SCH) and for the uppermost level of the vertical profile (SCV) at the borehole B14 position between April and November 2009. Periods I-IV are described in the text. Note only lines with black symbols are measured at exactly coincident locations, as the distance between the SISOMOP sensor and the borehole is about $2 \mathrm{~m}$.

without a renewed increase, the resistivity for B100 decreased strongly on 24 May to a minimum below $1000 \Omega \mathrm{m}$.

At depths of around 3-5 m, resistivity first increased until the thawing processes began around 20 May and declined to a minimum value on 26 May. Finally, near the lower end of the tomogram at 10-m depth, resistivities gradually increased due to the correspondingly decreasing temperatures at that depth. In contrast, resistivities for the B100 show only small temporal changes below a depth of 2.5-m depth, apart from the initial thawing event on 22 May.

\section{Summer Season}

As shown above, temporal resistivity changes are either in phase with changes in soil moisture or with changes in subsurface temperature indicating the respective contributions of heat conduction and infiltration processes to thawing of the active layer during the snow-free period.

The impact on apparent resistivity of individual infiltration events associated with heavy rain can be identified from the soil moisture record. A prominent example is the strong resistivity decrease observed on 2 September at both boreholes at $0.25-\mathrm{m}$ depth as well as at 5.5-m depth at B14 (Figure 11). This decrease was due to heavy rain and a thunderstorm event which caused a power failure at the base station Birg and resulted in the subsequent data gap visible in Figure 11. Similar rain-induced infiltration events occurred on 25 August and 10 October, and are marked by resistivity decreases and accompanying soil moisture increases (cf. Figure 8).

The resistivity change in the near-surface is very similar at both boreholes (black symbols in Figure 11). But whereas the resistivity at 5.5-m depth decreases strongly during summer near B14 due to the infiltration events, no similarly large resistivity changes occur near B100 at 5.5-m depth. This difference in behaviour is caused by the still-frozen subsurface conditions near B100 at this depth (maximum active-layer depth of $5 \mathrm{~m}$ in 2009), in contrast to the thawed and therefore permeable conditions near B14 (maximum active-layer depth of $7 \mathrm{~m}$ ).

The conspicuous resistivity increase in the near-surface at the beginning of October is caused by a sudden air 

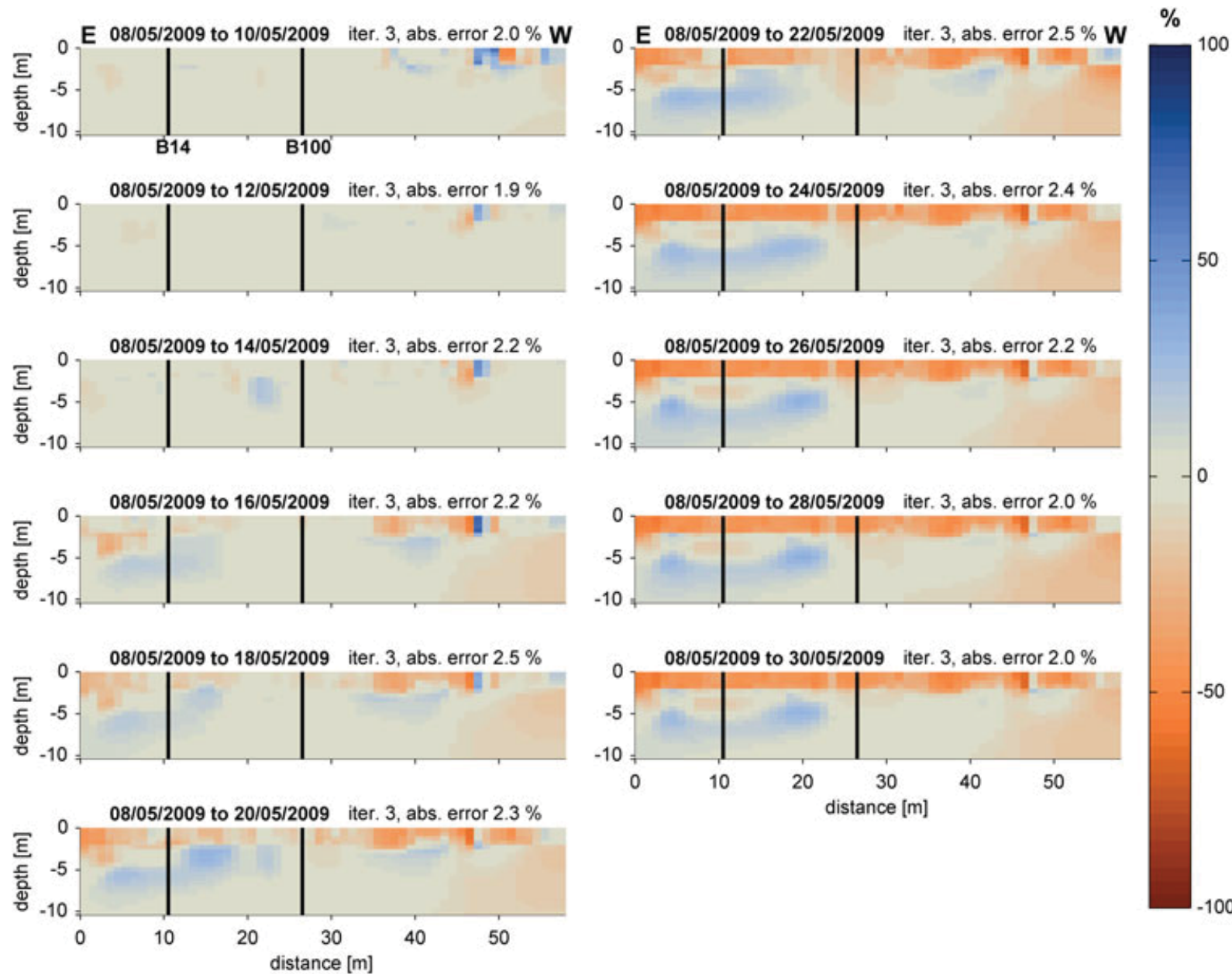

Figure 9 Calculated resistivity changes for every second day in the period between 8 and 30 May 2009 relative to the electrical resistivity tomography dataset from 8 May 2009.

temperature decrease leading to frozen conditions. Finally, the slow but continuous increase in resistivity from the second week of October onwards marks the arrival of a continuous snow cover and the subsequent re-freezing of the active layer from above. This process happens contemporaneously at both boreholes and is not seen at 5.5-m depth.

\section{SUMMARY AND CONCLUSIONS}

We describe a new approach for A-ERT measurements in mountainous terrain. The system is based on an existing Geotom multi-electrode resistivity instrument (Geolog) and includes a solar panel-driven battery and remote data transfer to a base station where the controlling computer is also located. The system allows a free choice of measurement interval and different electrode configurations.

The first prototype system was installed at the existing ERT monitoring profile on Schilthorn, Swiss Alps, where manual measurements have been conducted since 1999 .
In its present configuration, Wenner, Wenner-Schlumberger and dipole-dipole measurements are conducted daily, with a reduction of dipole-dipole measurement frequency during winter. The operational test phase started in April 2009 yielding a one-year A-ERT dataset for analysis, but including several data gaps due to power failures at the base station Birg.

The results show that A-ERT monitoring is capable of generating stable and valuable 2D time series of apparent and inverted specific resistivity datasets provided that the contact resistances remain low throughout the year. To be able to process this large amount of data in an efficient way, data-processing algorithms, including filtering, despiking, batch-inversion and illustration were automated. The results are presented as time series of specific and mean apparent resistivities, time series of tomograms and virtual boreholes for different time steps.

The potential benefit of acquiring continuous resistivity data with a regular time interval was analysed regarding seasonal change (infiltrating meltwater from the snow cover 

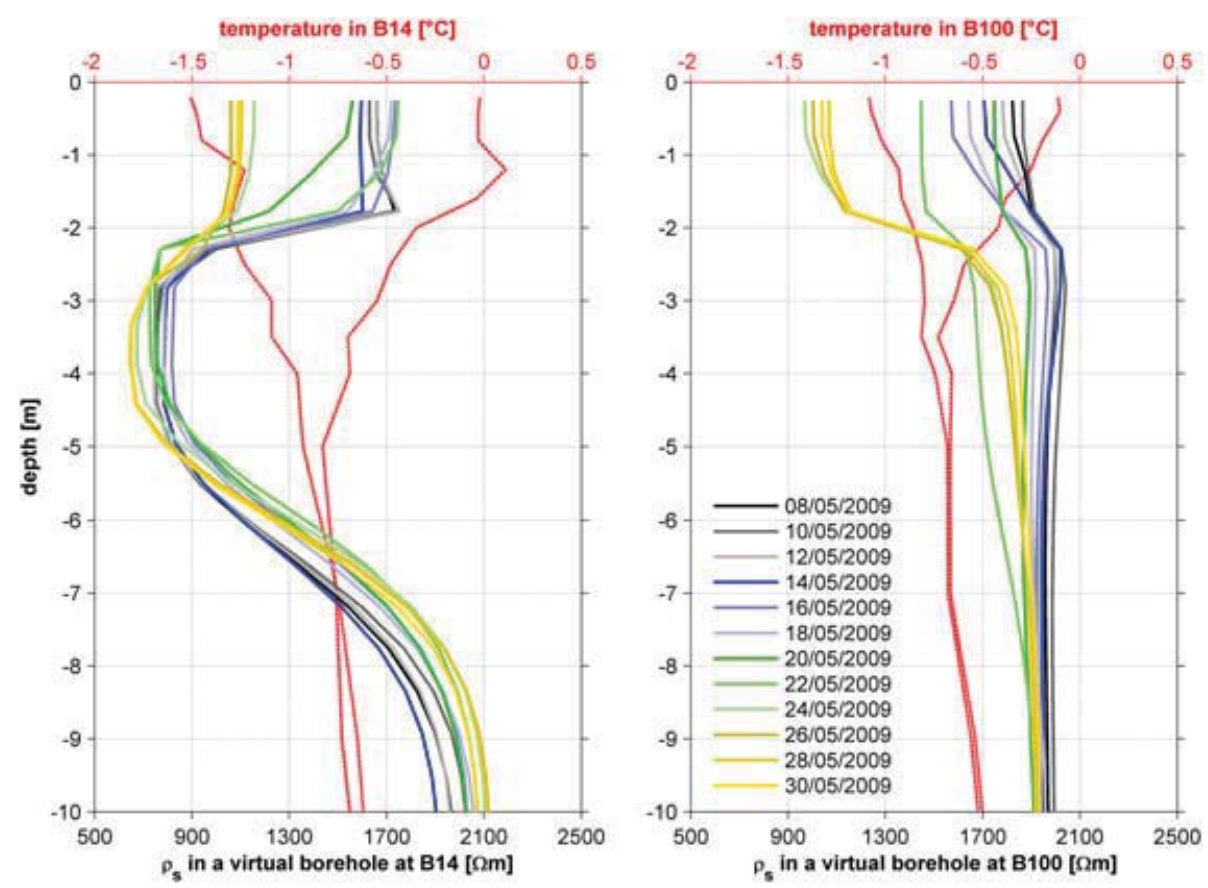

Figure 10 Specific resistivity values at the B14 and B100 sites taken from various inverted tomograms for the thawing season 2009. The red lines (upper axes) show borehole temperatures for the first and last day of the period (8 and 30 May).

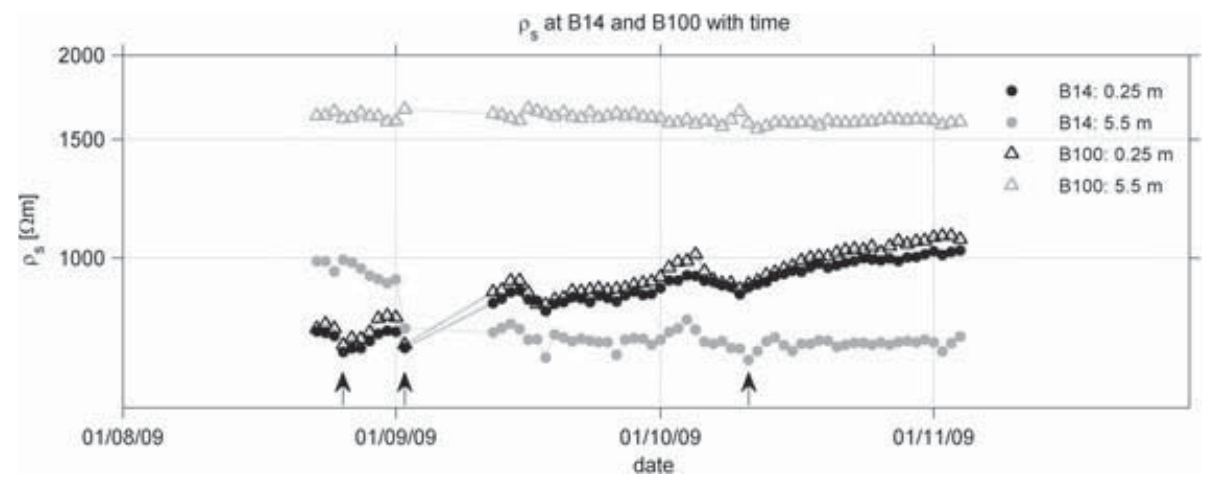

Figure 11 Evolution of specific resistivities taken from the inversion tomograms at boreholes B14 and B100 through time for two different depths during August to November 2009. Arrows mark the infiltration events discussed in the text.

into thawing active layer in late spring) and long-term change (1999-2010) at Schilthorn. Measurements during the thaw season in May 2009 revealed that infiltrating water from the melting snow cover induces the beginning of thaw processes in the active layer and the onset of the zerocurtain within only a few days and long before the snow cover completely ablates in July. This process was simultaneously observed in soil moisture and soil temperature data along the ERT line. The spatial heterogeneity of active-layer thawing as well as rain-induced infiltration events during summer could be detected by the 2D ERT approach.

Analysis of the temporal evolution of spatial mean apparent resistivity data showed that annual minimum resistivity values may be found in different months in different years, in part depending on the choice of date for which the resistivity changes are evaluated. Before automation, minimum values were observed in October in 2008, in September in 2002 and 2007, and in August in 2000 and 2003. In the absence of continuous data, it is not clear whether the timing of these minima is a consequence of the irregular data acquisition or the prevailing meteorological conditions.

Based on these first experiences with automated and continuously measured ERT datasets, we believe that this A-ERT system has high potential for future application in remote high-mountain and polar permafrost environments. 


\section{ACKNOWLEDGEMENTS}

We would like to thank the Schilthornbahn AG for their continuous and long-term support of the permafrost research at Schilthorn. We also thank Jeannette Noetzli for providing the PERMOS borehole temperatures. Improvements suggested by the reviewer and the Editor are greatly acknowledged. This study was funded by the PERMOS network (BAFU, Switzerland) and the Deutsche Forschungsgemeinschaft (DFG MA1308_22-1 and DFG HA3475/3-1).

\section{REFERENCES}

Aaltonen J, Olofsson B. 2002. Direct current (DC) resistivity measurements in long-term groundwater monitoring programmes. Environmental Geology 41(6): 662-671. DOI: 10.1007/s00254-001-0447-1.

Edwards LS. 1977. Modified pseudo-section for resistivity and IP. Geophysics 42(5): 1020-1036. DOI: 10.1190/1.1440762.

Fortier R, LeBlanc AM, Allard M, Buteau S, Calmels F. 2008. Internal structure and conditions of permafrost mounds at Umiujaq in Nunavik, Canada, inferred from field investigation and electrical resistivity tomography. Canadian Journal of Earth Sciences 45: 367-387. DOI: 10.1139/E08-004.

French H, Binley A. 2004. Snowmelt infiltration: monitoring temporal and spatial variability using time-lapse electrical resistivity. Journal of Hydrology 297: 174-186. DOI: 10.1016/j.jhydrol.2004.04.005.

Hauck C. 2002. Frozen ground monitoring using DC resistivity tomography. Geophysical Research Letters 29(21): 2016. DOI: 10.1029/ 2002 GL014995.

Hauck C, Kneisel C (eds). 2008. Applied Geophysics in Periglacial Environments. Cambridge University Press, Cambridge: 240.

Hauck C, Böttcher M, Maurer, H. 2011. A new model for estimating subsurface ice content based on combined electrical and seismic data sets. The Cryosphere 5: 453-468. DOI: $10.5194 / \mathrm{tc}-5-453-2011$.

Hausmann H, Krainer K, Brückl E, Mostler W. 2007. Internal structure and ice content of Reichenkar rock glacier (Stubai Alps, Austria) assessed by geophysical investigations. Permafrost and Periglacial Processes 18(4): 351-367. DOI: 10.1002/ppp.601.

Hilbich C. 2010. Time-lapse refraction seismic tomography for the detection of ground ice degradation. The Cryosphere 4: 243-259. DOI:10.5194/tc-4-243-2010.

Hilbich C, Hauck C, Delaloye R, Hoelzle M. 2008b. A geoelectric monitoring network and resistivity-temperature relationships of different mountain permafrost sites in the Swiss Alps. In 9th International Conference on Permafrost. DL Kane, KM Hinkel (eds.). Institute of Northern Engineering, University of Alaska Fairbanks: Fairbanks, Alaska; Volume I: 699-704.
Hilbich C, Hauck C, Hoelzle M, Scherler M, Schudel L, Völksch I, Vonder Mühll D, Mäusbacher R. 2008a. Monitoring mountain permafrost evolution using electrical resistivity tomography: A 7-year study of seasonal, annual, and long-term variations at Schilthorn, Swiss Alps. Journal of Geophysical Research 113: F01S90. DOI: 10. 1029/2007JF000799.

Hilbich C, Marescot L, Hauck C, Loke MH., Mäusbacher R. 2009. Applicability of Electrical Resistivity Tomography Monitoring to coarse blocky and ice-rich permafrost landforms. Permafrost and Periglacial Processes 20(3): 269-284. DOI: 10.1002/ppp.652.

Kneisel C, Hauck C. 2008. Electrical methods. In Applied Geophysics in Periglacial Environments, Hauck C, Kneisel C (eds). Cambridge University Press: Cambridge; 3-27.

Kneisel C, Hauck C, Fortier R, Moormann B. 2008. Advances in geophysical methods for permafrost investigation. Permafrost and Periglacial Processes 19: 157-178. DOI: $10.1002 /$ ppp.616.

Krauss L, Hauck C, Kottmeier C. 2010. Spatio-temporal soil moisture variability in Southwest Germany observed with a new monitoring network within the COPS domain. Meteorologische Zeitschrift. DOI 10. 1127/0941-2948/2010/0486.

Kuras O, Pritchard J, Meldrum PI, Chambers JE, Wilkinson PB, Ogilvy RD., Wealthall GP. 2009. Monitoring hydraulic processes with Automated time-lapse Electrical Resistivity Tomography (ALERT). Comptes Rendus Geosciences 341(10-11): 868-885, DOI: 10. 1016/j.crte.2009.07.010

LaBrecque DJ, Heath G, Sharpe R, Versteeg R. 2004. Autonomous monitoring of fluid movement using 3-D Electrical Resistivity Tomography. Journal of Environmental and Engineering Geophysics 9: 167-176. DOI:10.4133/JEEG9.3.167.

Marescot L, Loke MH, Chapellier D, Delaloye R, Lambiel C, Reynard E. 2003. Assessing reliability of $2 \mathrm{D}$ resistivity imaging in mountain permafrost studies using the depth of investigation index method. Near Surface Geophysics 1(2): 57-67. DOI: 10.3997/18730604.2002007.

Ogilvy RD, Kuras O, Meldrum PI, Wilkinson PB, Gisbert J, Jorreto S, Frances I, Pulido Bosch A. 2009. Automated time-Lapse Electrical
Resistivity Tomography (ALERT) for monitoring Coastal Aquifers. Near Surface Geophysics 7: 367-375. DOI: 10.3997/ 1873-0604.2009027.

PERMOS. 2009. Permafrost in Switzerland 2004/2005 and 2005/2006, Glaciological Report (Permafrost) No. 6/7, Noetzli J, Naegeli B, Vonder Muehll D (eds). Cryospheric Commission of the Swiss Academy of Sciences, Bern: 100.

Scherler M, Hauck C, Hoelzle M, Stähli M, Völksch I. 2010. Meltwater infiltration into the frozen active layer at an alpine permafrost site. Permafrost and Periglacial Processes 21: 325-334. DOI: 10.1002/ ppp.694.

Schlaeger S, Hübner C, Becker R. 2005. Simple soil moisture probe for low-cost measurement applications. In Proceedings of the 6th Conference on 'Electromagnetic Wave Interaction with Water and Moist Substances', K. Kupfer (ed.). ISEMA 2005, Weimar, Germany, May 29-June 1, 2005. Materialprüfungsanstalt Weimar. 258-265.

Scott WJ, Sellmann PV, Hunter JA. 1990. Geophysics in the study of permafrost. In Geotechnical and Environmental Geophysics, Ward S (ed). Tulsa; 355-384.

Sjödahl P, Dahlin T, Johansson S, Loke MH. 2008. Resistivity monitoring for leakage and internal erosion at Hällby embankment dam. Journal of Applied Geophysics 65: 155-164. DOI: 10.1016/j.jappgeo.2008. 07.003 .

Versteeg R, Ankeny M, Harbour J, Heath G, Kostelnik K, Mattson E, Moor K, Richardson A, Wangerud K. 2004. A structured approach to the use of near-surface geophysics in long-term monitoring, The Leading Edge 23: 700-703. DOI: 10.1190/1.1776745

Westermann S, Lüers J, Langer M, Piel K, Boike J. 2009. The annual surface energy budget of a high-arctic permafrost site on Svalbard, Norway. The Cryosphere 3(2): 245-263. DOI: 10.5194/tc-3-245-2009.

Zhang Y, Carey SK, Quinton WL., Janowicz JR, Pomeroy JW, Flerchinger GN. 2010. Comparison of algorithms and parameterisations for infiltration into organiccovered permafrost soils. Hydrology and Earth System Sciences 14: 729-750. DOI: 10.5194/hess-14-729-2010. 